\title{
The nanostructure and microstructure of steels: Electrochemical Tafel behaviour and atomic force microscopy
}

\author{
Valéria A. Alves a, Ana M. Chiorcea Paquim ${ }^{\mathrm{b}}$, \\ Albano Cavaleiro ${ }^{c}$, Christopher M.A. Brett ${ }^{\text {b,* }}$ \\ a Departamento de Farmácia-Bioquímica, Faculdades Federais Integradas de Diamantina, \\ FAFEID, Rua da Glória, 187 Centro 39100-000 Diamantina, Minas Gerais, Brazil \\ b Departamento de Química, Universidade de Coimbra, 3004-535 Coimbra, Portugal \\ c Departamento de Engenharia Mecânica, Universidade de Coimbra, 3030 Coimbra, Portugal
}

Available online 9 September 2005

\begin{abstract}
The influence of chemical composition and heat treatment on a low-carbon steel, chromium steel and high speed steel has been examined by polarisation curves and electrochemical parameters deduced from the Tafel plots. The electrochemical corrosion resistance, which is small between the as-received steels become greater after heat treatment, following the order: carbon steel $<$ chromium steel $\sim$ high speed steel. To explain these differences, the nano- and microstructure of the steels has been characterized by the ex situ techniques of atomic force microscopy and optical microscopy, before and after surface etching with Nital (a solution of $5 \% \mathrm{HNO}_{3}$ in ethanol). This causes preferential attack of the ferrite phases showing the carbide phases more clearly. From these nanostructural studies it was possible to better understand why the passive films formed on chromium steel and high speed steel have superior protective properties to those formed on carbon steel.
\end{abstract}

(c) 2005 Elsevier Ltd. All rights reserved.

Keywords: Carbon steel; Chromium steel; High speed steel; Carbides; Tafel plots; Atomic force microscopy

\footnotetext{
* Corresponding author. Tel./fax: +351 239835295.

E-mail address: brett@ci.uc.pt (C.M.A. Brett).
} 


\section{Introduction}

The behaviour and performance of steels is intimately linked to their chemical and phase composition, structure and surface morphology [1]. Measurements such as open circuit potential and polarisation curves in the form of Tafel plots have been particularly useful and elucidative in corrosion studies, since there is usually a significant overpotential for both anodic and cathodic processes and the values of the current vary over several orders of magnitude. Application of the Tafel equation [2] can give important information such as the corrosion potential, $E_{\text {cor }}$, the corrosion current, $I_{\text {cor }}$, and the anodic and cathodic Tafel slopes, which are a function of the charge transfer coefficient. Comparison of $E_{\text {cor }}$ with the open circuit potential values, $E_{\text {ocp }}$, is important in order to ascertain the influence of having applied a potential to the corroding surface different from the natural one during the recording of the polarisation curves. The electrochemical information obtained, together with that from other techniques such as electrochemical impedance spectroscopy, is valuable but complementary techniques are useful to understand the sub-microscopic behaviour of the corroding steel surface, whose performance is intimately linked to chemical composition, the phases present and their microstructure, which are altered through quenching, tempering and annealing processes.

Only recently has it become possible to examine the morphology of solid surfaces at the nanoscale using local probe techniques [3]. Corrosion parameters inferred from changes in open circuit potential with time, Tafel curves or electrochemical impedance spectra are the result of averages made over the sample surface [4]. Local probe techniques that can be employed include scanning tunnelling microscopy (STM) and atomic force microscopy (AFM) [3] as well as, for electrochemical studies in electrolyte, the scanning Kelvin probe [5]. For examination in air, AFM has the advantage that it measures the force between the scanning cantilever arm and the substrate, whereas STM relies on the passage of a tunnelling current, which may not be possible on an oxidised surface, as can occur with metal surfaces covered with semiconducting oxide.

Some recent examples of the use of AFM for studying metal surfaces may be found in Refs. [6-18]. The properties of passive films on an iron surface were studied in Ref. [7], it being conclusively demonstrated that the defects in the film was where corrosion initiated; the STM of iron surfaces evidenced its nanocrystallinity [19]. AFM has been used to study stainless steels with regard to electropolishing, in order to better understand the origin of the electrobrightening effect [7], the topography of duplex stainless steels [8], and the adsorption of proteins [9]. The effect of corrosion products on SUS304 stainless steel pitting was studied by AFM [10] and pitting at $\mathrm{MnS}$ inclusions in 316 stainless steels was investigated by a combination of AFM, scanning vibrating electrode technique (SVET) and Auger electron spectroscopy [11]. Correlations of AFM results with mechanical testing of steels were done for fatigue crack nucleation [12], examination of and surface deformation at grain boundaries [13,14], strength analysis by nanoindentation [15] and after surface modification procedures to reduce fouling [16]. AFM was also used to surface image AISI 
D2 tool steel machined by electrical discharge [17] and the effect of oxide film growth on low-carbon steel at high temperatures [18].

In previous work, we have examined three different types of steel and differences in their corrosion behaviour as well as the effect of heat treatment [20-23]. These were a carbon steel, AISI 1015, a chromium steel and M2 high speed steel. High speed steel shows the typical behaviour of an easily corroded steel in saline medium [20]; the corrosion resistance increases after heat treatment [21] as it does for all these three types of steel [22]. The structure and semiconductor properties of passive films formed on the surface of these steels is different and is influenced by heat treatment $[23,24]$. The strength of the steels depends significantly on the chemical composition of the carbide phases and grain size, which can alter with heat treatment. This also has important effects on the electrochemical behaviour of steels with hard coatings [24].

In this paper the information on the corrosion resistance of the steels mentioned above obtained before and after heat treatment, particularly from values of corrosion potential and corrosion current deduced from Tafel plots, has been complemented with surface morphology studies. The steel samples have been examined by AFM, and Optical Microscopy (OM) before and after chemical attack with Nita1 etching solution (a solution of $5 \% \mathrm{HNO}_{3}$ in ethanol), used in order to evidence the microstructure of the steels.

\section{Experimental}

\subsection{Chemical composition, heat treatment and surface preparation of the steels}

The chemical composition of the three different types of steels studied: carbon steel, chromium steel and high speed steel are shown in Table 1. Carbon steel was used as-received; chromium steel and high speed steel were used as-received and after heat treatment.

Heat treatment consisted of the following steps:

(a) Austenitizing at $950{ }^{\circ} \mathrm{C}$ (chromium steel) or at $1200{ }^{\circ} \mathrm{C}$ (high speed steel) for 10 min in argon atmosphere, (b) quenching in oil down to room temperature, and

Table 1

Nominal chemical composition in wt.\% of the steels studied

\begin{tabular}{llllllrl}
\hline Steel type & W & Mo & Cr & V & C & Mn & Si \\
\hline Carbon steel 1015 (AISI) & - & - & - & - & 0.17 & $<1.0$ & $<0.4$ \\
Chromium steel CALMAX $^{\circledR}$ & - & 0.5 & 4.5 & 0.2 & 0.6 & 0.8 & $<0.4$ \\
High speed steel M2 (AISI) & 6.4 & 5.0 & 4.2 & 1.9 & 0.9 & $<0.4$ & $<0.4$ \\
\hline
\end{tabular}


(c) single tempering of $2 \mathrm{~h}$ at $450^{\circ} \mathrm{C}$ (chromium steel) or triple tempering of $2 \mathrm{~h}$ each at $550^{\circ} \mathrm{C}$ or $650^{\circ} \mathrm{C}$ (high speed steel).

After heat treatment, some samples were mounted for electrochemical experiments, the unmounted samples being used for chemical etching and microscopic observation. A copper wire was attached to the rear face of the steel samples with silver epoxy which was then covered with epoxy resin, as well as the edges of the samples.

The exposed faces of samples mounted as electrodes as well as one of the faces of the unmounted samples were polished with silicon carbide papers of various grit sizes $(240,320,600,800,1200$ and 2500), and finally with diamond paste of $6 \mu \mathrm{m}$ diameter particle size, until a mirror finish was obtained. They were then rinsed with acetone and ethanol in an ultrasound bath.

\subsection{Etching of steels with Nital}

Nital, the solution used for revealing the nano- and microstructure of the steels, was prepared by mixing $5 \mathrm{~mL}$ of ethanol (Merck) with $95 \mathrm{~mL}$ of concentrated nitric acid (Merck). The chemical attack occurs preferentially in zones where chemical oxidation is easiest thus showing the microstructure in better detail.

A piece of paper was wetted with Nital and put in contact with the steel sample for about $1 \mathrm{~min}$. The samples were then rinsed with water, dried and examined by optical microscopy, OM, and by atomic force microscopy, AFM.

\subsection{Equipment and experimental procedures}

For electrochemical experiments, non-deaerated solutions of $0.1 \mathrm{M} \mathrm{KCl}$ and $0.5 \mathrm{M} \mathrm{NaHCO}_{3}+0.01 \mathrm{M} \mathrm{KCl}$ were prepared using analytical grade reagents and Millipore Milli-Q water (resistivity $>18 \mathrm{M} \Omega \mathrm{cm}$ ). A three-electrode one-compartment cell, containing a Pt foil auxiliary electrode and a saturated calomel electrode (SCE) as reference was employed. Polarisation curves were registered using a PCcontrolled EG\&G PAR 273A potentiostat (Princeton Applied Research, Princeton, NJ, USA), running M352 software, which was also used to adjust the Tafel curves for calculating corrosion currents.

Optical microscopy was carried out with an Optiphot-2 type 115 microscope (Nikon, Japan) equipped with a digital camera.

AFM was performed with a Pico SPM (Molecular Imaging Co., USA) controlled by a Digital Instruments Nanoscope E controller (Veeco Instruments, USA). All the AFM experiments were performed with an AFM M scanner with a scan range $30 \mu \mathrm{m}$ in $x-y$ and $7 \mu \mathrm{m}$ in $z$, (Molecular Imaging Co., USA). Silicon nitride NanoProbes ${ }^{\mathrm{TM}}$ V-shaped cantilevers, $100 \mu \mathrm{m}$ length, $0.58 \mathrm{~N} \mathrm{~m}^{-1}$ spring constant were used. All images were taken in contact mode AFM in air at room temperature. The images were processed by flattening in order to remove the background slope, and the contrast and brightness were adjusted. 


\section{Results and discussion}

\subsection{Tafel plots and chemical attack by Nital}

Typical Tafel plots of the different steels under consideration after $4 \mathrm{~h}$ immersion in $0.1 \mathrm{M} \mathrm{KCl}$ solution are shown in Fig. 1. Table 2 gives average values of the corrosion currents and corrosion potentials for three samples after $1 \mathrm{~h}$ and $4 \mathrm{~h}$ immersion. The anodic Tafel slopes are all very similar. These data lead to the conclusion, which can be deduced from Table 2 and [21], that heat treatment leads to increased corrosion resistance, particularly regarding pitting corrosion, probably because a higher quantity of alloying elements remains in solid solution. Increasing immersion time above $1 \mathrm{~h}$ does not lead to significant changes in $E_{\text {cor }}$ or $I_{\text {cor }}$. These studies were supported by X-ray diffraction of the sample surfaces before and after corrosion but no direct evidence of the state of the sample surfaces was presented.

Therefore, here the different steel samples were treated with Nital (solution 5\% $\mathrm{HNO}_{3}$ in ethanol), in order to reveal their nanostructure, which should give some insight into their electrochemical behaviour, e.g. pitting corrosion and passivation properties. The effects on each type of steel will be discussed in turn. In this context and the possible information that can be obtained concerning steel microstructure, an in situ investigation study on the corrosion of duplex stainless steel by Aldykiewicz and Isaacs [25] should be mentioned, which involved its dissolution behaviour in acidic solution using local probe current density mapping techniques. Local variations between the dissolution rates on the austenite and ferrite phases were observed, the latter being attacked preferentially. Recently, Schmidt-Rieder et al. [26] have studied the early stages of corrosion on duplex stainless steel in aqueous $\mathrm{NaCl}$ solution by using electrochemical STM and AFM, in situ and in real time, in which the preferential attack of the ferrite phase was also observed in the images obtained.

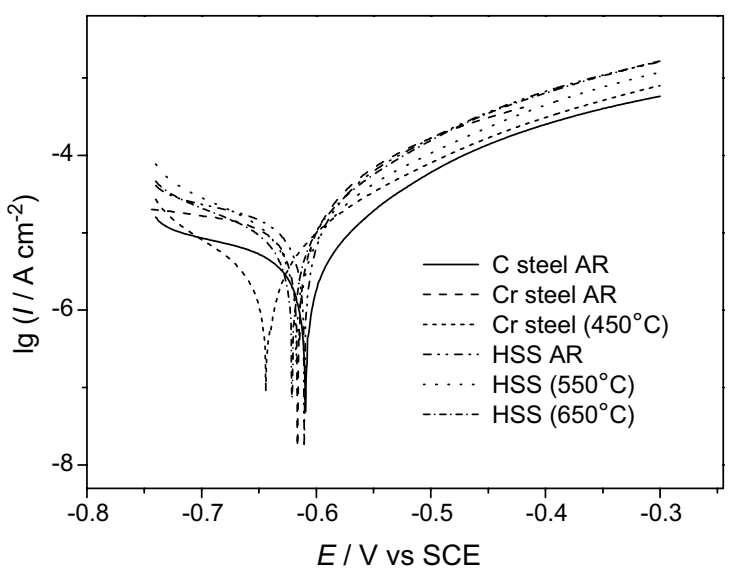

Fig. 1. Tafel plots of the steels studied in $0.1 \mathrm{M} \mathrm{KCl}$, scan rate $2.5 \mathrm{mV} \mathrm{s}^{-1}$ : AR-as-received; heat treatment temperatures in brackets. 
Table 2

Corrosion parameters from analysis of Tafel plots for $1 \mathrm{~h}$ and $4 \mathrm{~h}$ immersion in $0.1 \mathrm{M} \mathrm{KCl}$

\begin{tabular}{|c|c|c|c|c|}
\hline & \multicolumn{2}{|c|}{$-E_{\mathrm{cor}} / \mathrm{V}$ vs SCE } & \multicolumn{2}{|c|}{$I_{\mathrm{cor}} / \mu \mathrm{A} \mathrm{cm} \mathrm{cm}^{-2}$} \\
\hline & $1 \mathrm{~h}$ & $4 \mathrm{~h}$ & $1 \mathrm{~h}$ & $4 \mathrm{~h}$ \\
\hline Carbon steel 1015 & 0.58 & 0.61 & 25.2 & 33.4 \\
\hline Chromium steel AR & 0.59 & 0.62 & 33.4 & 34.8 \\
\hline Chromium steel $\left(450^{\circ} \mathrm{C}\right)$ & 0.60 & 0.64 & 10.1 & 11.0 \\
\hline HSS AR & 0.59 & 0.61 & 30.6 & 32.4 \\
\hline $\operatorname{HSS}\left(550^{\circ} \mathrm{C}\right)$ & 0.60 & 0.62 & 11.2 & 17.7 \\
\hline $\operatorname{HSS}\left(650^{\circ} \mathrm{C}\right)$ & 0.59 & 0.62 & 15.4 & 16.2 \\
\hline
\end{tabular}

AR: as-received; tempering temperatures within brackets.

\subsection{Carbon steel}

Micrographs of carbon steel obtained by optical microscopy (OM) showed two dominant phases, Fig. 2, which are ferrite grains as well as pearlite, a lamellar mixture of ferrite (alpha-iron) and iron carbide or cementite, which corresponds to the darker parts of the micrograph. This same microstructure has been observed for A516-70 carbon steel [27]. The images obtained by atomic force microscopy, AFM, of this steel allow us to visualize the lamellar characteristic of the pearlitic structure in the centre of the image in addition to the ferrite grains (Fig. 3A). This lamellar structure was not observed in the AFM images of steel before attack by Nital. The structure of the ferrite grains can also be observed in the AFM image with reduced scan-size in Fig. 3B.

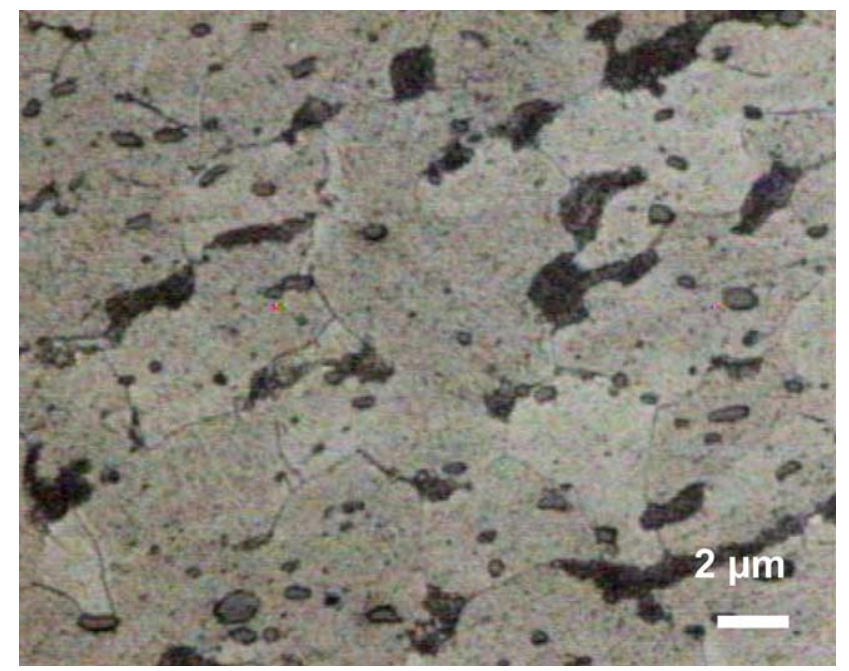

Fig. 2. Optical microscopy of carbon steel treated with Nital, showing the ferrite and the pearlite phases. Magnification: $500 \times$. 

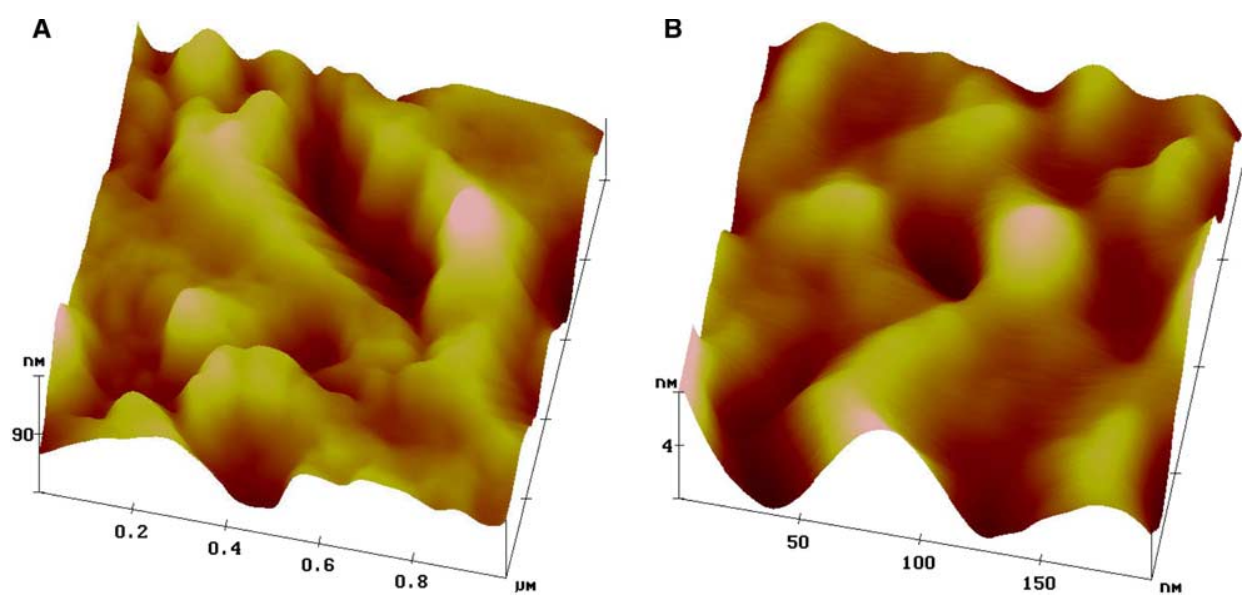

Fig. 3. Three-dimensional AFM topographical images of different areas of carbon steel treated with Nital: note the different vertical as well as horizontal scales.

\subsection{Chromium steel}

From the micrograph obtained by OM of chromium steel it was not possible to define a particular microstructure, as in the case of carbon steel. However, the AFM images of this steel treated with Nital, Fig. 4, revealed a very interesting nanostructure after heat treatment, totally different from that of carbon steel. The presence of spheroidal particles of $\sim 40 \mathrm{~nm}$ diameter size is observed, preferentially in the grain boundaries of ferrite $(\sim 250 \mathrm{~nm}$ grain size) (see Fig. 4B). The
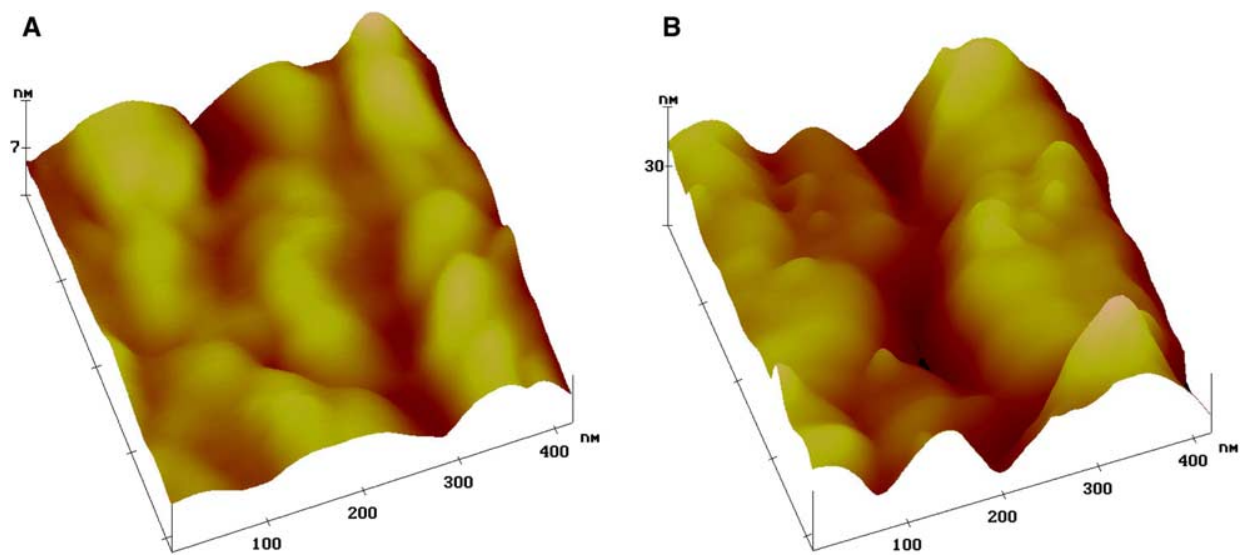

Fig. 4. Three-dimensional AFM topographical images of chromium steel tempered at $450{ }^{\circ} \mathrm{C}$ : (A) before and (B) after attack with Nital. Note the different vertical scales. 
AFM image of this steel before attack with Nital revealed essentially the same microstructure, although less clearly, as could be expected (compare Fig. 4A and B). This information allows us to attribute the particles of $\sim 40 \mathrm{~nm}$ diameter size to chromium carbide, $\mathrm{Cr}_{7} \mathrm{C}_{6}$ or $\mathrm{Cr}_{23} \mathrm{C}_{6}$, probably formed during the tempering step at $450^{\circ} \mathrm{C}$.

In steels with chromium contents lower than $4 \%$, the transformation of $\mathrm{Fe}_{3} \mathrm{C}$ in $\mathrm{Cr}_{7} \mathrm{C}_{6}$ occurs mainly by nucleation in the $\mathrm{Fe}_{3} \mathrm{C} /$ ferrite interfaces. The grain size attributed to the ferrite seems to be abnormally low for this type of steel (usually of the order of some micrometres). However, the precipitation of the $\mathrm{Cr}$ carbides can very probably induce a depletion of this element locally in the ferrite grains in such a way that in some zones deeper corrosion occurred giving rise to this granular aspect which is misleading in relation to the true grain size. Chromium diffusion is very fast in ferrite in comparison to other metallic elements, thus contributing to the heterogeneous distribution in the ferrite grains.

\subsection{High speed steel}

Attack with Nital was also done for high speed steel as-received, and after quenching and tempering at two different temperatures: $550{ }^{\circ} \mathrm{C}$ and $650{ }^{\circ} \mathrm{C}$. AFM images are shown in Fig. 5. It can be observed that the micro- and nanostructure of HSS tempered at $550{ }^{\circ} \mathrm{C}$, Fig. $5 \mathrm{~B}$, and $650{ }^{\circ} \mathrm{C}$, Fig. $5 \mathrm{C}$, is more well defined than that of HSS as-received, Fig. $5 \mathrm{~A}$ and that they were less etched. After tempering, the presence of two phases can be inferred: one which apparently was attacked and another resembling "islands", which remained intact. These results are further evidence that the heat treatment of HSS leads to modification of its microstructure, in agreement with the different electrochemical behaviour of this steel after thermal treatment, specifically the higher corrosion resistance [22].

The phase that is present in the microstructure of HSS after heat treatment, and is preferentially attacked by Nital, is related to the ferrite matrix [20-22], while the nature of the other phase ("islands") must be identified by a complementary technique. From the AFM images it is possible to note the presence of areas of a few $\mu \mathrm{m}$ size, distributed on the surface of HSS, which could be related to carbides of the alloying elements. It should be noted, however, that not all of the steel surface evidenced this higher concentration of carbides.

\subsection{Correlation between nanostructure of steels and their corroding and passivating properties}

From the electrochemical experiments in a solution that promotes the formation of a passive oxide film on the steel surface and then its breaking (e.g. $0.5 \mathrm{M} \mathrm{NaH}$ $\mathrm{CO}_{3}+0.01 \mathrm{M} \mathrm{KCl}$ [23]), it was concluded that the following order of corrosion resistance can be established:

carbon steel $<$ chromium steel $<$ high speed steel 

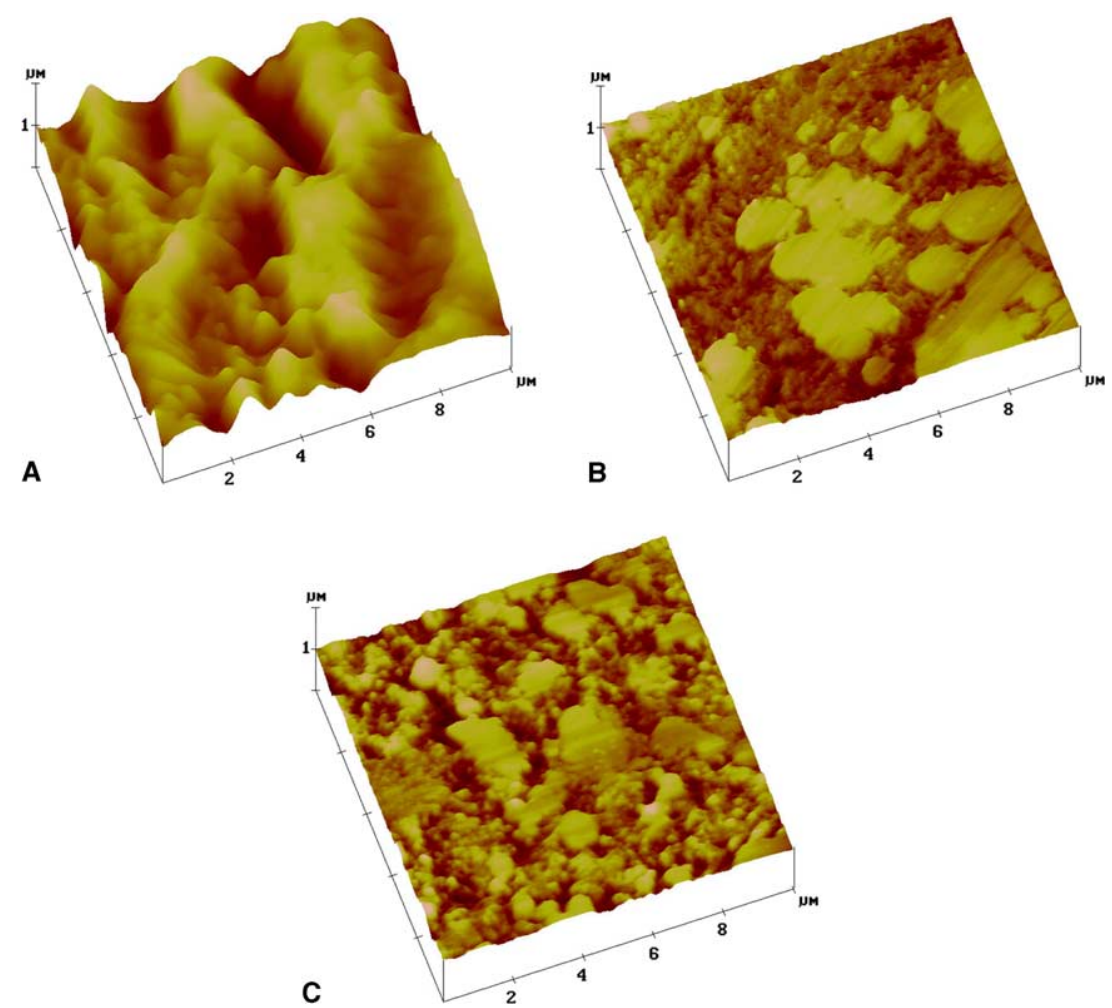

Fig. 5. Three-dimensional AFM topographical images of high speed steel (A) as-received and heat-treated at (B) $550{ }^{\circ} \mathrm{C}$ and (C) $650{ }^{\circ} \mathrm{C}$ after attack by Nital.

Polarisation curves are shown in Fig. 6. The lower corrosion resistance of carbon steel is probably related to the absence of alloying elements, which are able to confer passivation or repassivation properties to the steel, mainly chromium in solid solution in the ferrite matrix, that exist in chromium and high speed steels.

The microstructure of chromium steel, as revealed by AFM, allowed us to better understand its passivating and corroding behaviour. After passivation in $0.5 \mathrm{M}$ $\mathrm{NaHCO}_{3}$, this steel, following heat treatment, had the smallest passivation currents, which means that the passive oxide film has the highest resistivity. This is corroborated by the interpretation given to the AFM image, where we can deduce that the features with $\sim 40 \mathrm{~nm}$ diameter size, present in the steel surface, are related to attack by Nital on the parts of the surface other than chromium carbide. Supporting this evidence, X-ray photoelectron spectroscopy (XPS) analysis confirmed the presence of $\mathrm{Cr}_{2} \mathrm{O}_{3}, \mathrm{Cr}(\mathrm{OH})_{3}$ and metallic $\mathrm{Cr}$ in the surface of chromium steel after $24 \mathrm{~h}$ immersion in $0.5 \mathrm{M} \mathrm{NaHCO}_{3}$ [28]. On the other hand, the fact that chromium is present in this steel microstructure as carbides, as well as in solid solution in the iron matrix, aids in understanding its behaviour with respect to pitting corrosion. The zones in the matrix around the Cr-rich carbide particles are, in turn, depleted in 


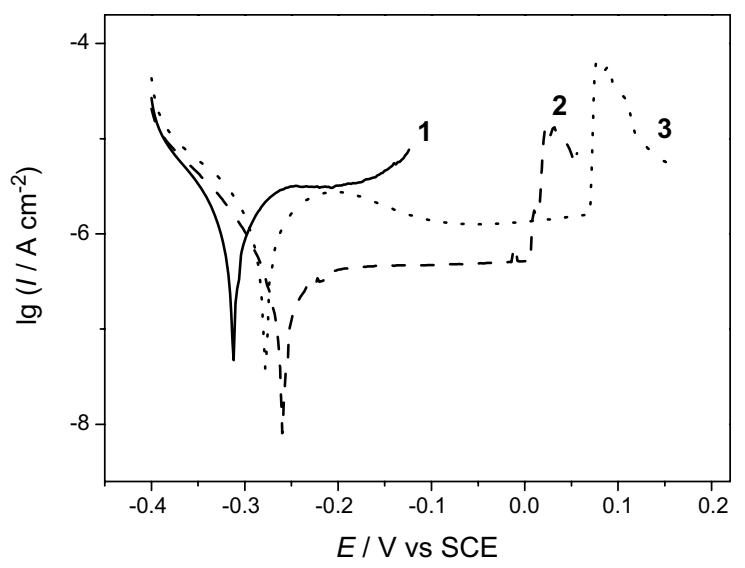

Fig. 6. Polarisation curves of the steel samples in $0.5 \mathrm{M} \mathrm{NaHCO}_{3}+0.01 \mathrm{M} \mathrm{KCl}$, scan rate $0.2 \mathrm{mV} \mathrm{s}^{-1}$. (1) Carbon steel; (2) chromium steel tempered at $450{ }^{\circ} \mathrm{C}$; (3) high speed steel tempered at $650{ }^{\circ} \mathrm{C}$.

chromium, becoming prone to localized attack, inducing, as referred to above, the misleading aspect of a nanosize grain dimension.

On the other hand, passivated high speed steel presented the best corrosion properties but at the same time the largest values of passivation currents [23]. It is expected that the smaller the value of the passive current, the higher the material's corrosion resistance, leading to an apparent contradiction. In fact, the passive oxide film formed in $0.5 \mathrm{M} \mathrm{NaHCO}_{3}$ contains Mo and $\mathrm{W}$ oxides, as shown by XPS, and in turn these oxides have a higher electrical conductivity than $\mathrm{Fe}$ and $\mathrm{Cr}$ oxides, which are the main components of the passive oxide films on carbon steel and chromium steel. Now it can also be understood why, although passivated HSS has a higher passive current value, it has more positive pitting potentials than passivated chromium steel or, in other words, the rupture of the passive film formed on HSS by the aggressive chloride ion is more difficult, as can be seen from the polarisation curves in Fig. 6. It is worth noting that the heat treatment of chromium steel [22] and high speed steel $[21,22]$ leads to increased corrosion resistance. This is probably due to a higher fraction of alloying elements remaining in solid solution after quenching and tempering in comparison to the annealed state in the as-received samples.

\section{Conclusions}

The studies of the micro- and nanostructure of the steels, carried out using AFM as well as optical microscopy, are in agreement with the electrochemical Tafel behaviour and corrosion resistance of the steels studied, and throw new light on the influence of the nanostructure in surface interactions with aggressive species in solution.

Carbon steel presented a microstructure formed by two dominant phases, identified as ferrite and pearlite. Since ferrite is attacked preferentially, it explains the worst corrosion behaviour of this steel. 
Chromium steel showed a very interesting microstructure through AFM, specifically spheroidal particles of $\sim 40 \mathrm{~nm}$ diameter size, attributed to chromium carbide, localized mainly in the grain boundaries of ferrite. This microstructure is in agreement with the electrochemical behaviour of the passivated steel, since the lowest passivation currents are characteristic of the low conductivity of chromium oxide which is formed. Since the chromium is present both in solid solution in the iron matrix and as carbides, this explains the steel's susceptibility to pitting corrosion.

High speed steel showed a microstructure with corrosion attributed mainly to the ferrite matrix. The Mo and $\mathrm{W}$ present in the matrix-forming solid solution as well as $\mathrm{Cr}$, leads to the highest corrosion resistance and at the same time their higherconductivity oxides are responsible for the highest passivation currents.

\section{Acknowledgements}

Financial support from Fundação para a Ciência e Tecnologia (FCT), post-doctoral Grant SFRH/BPD/14425/2003 (A.-M.C.P.), ICEMS (Research Unit 103), Portugal are gratefully acknowledged. V.A.A. thanks CNPq (Brazil), project 200396/99-4, for a post-doctoral fellowship.

\section{References}

[1] R.W.K. Honeycombe, H.K.D.H. Bhadeshia, Steels: Microstructure and Properties, second ed., Butterworth-Heinemann, Oxford, 1995.

[2] J. Tafel, Z. Phys. Chem. 50 (1905) 641.

[3] M. Miles, Science 277 (1997) 1845.

[4] R.G. Kelly, J.R. Scully, D.W. Shoesmith, R.G. Buchheit (Eds.), Electrochemical Techniques in Corrosion Science and Engineering, Dekker, NY, 2002.

[5] P. Schmutz, G.S. Frankel, J. Electrochem. Soc. 146 (1999) 4461.

[6] J. Li, D.J. Meier, J. Electroanal. Chem. 454 (1998) 53.

[7] V. Vignal, J.C. Roux, S. Flandrois, A. Fevrier, Corros. Sci. 42 (2000) 1041.

[8] A. Dias, M.S. Andrade, Appl. Surf. Sci. 161 (2000) 109.

[9] M. Vinnichenko, Th. Chevolleau, M.T. Pham, L. Poperenko, M.F. Maitz, Appl. Surf. Sci. 201 (2002) 41.

[10] Q. Zhang, R. Wang, M. Kato, K. Nakasa, Scripta Mater. 52 (2005) 227.

[11] B. Vuillemin, X. Philippe, R. Oltra, V. Vignal, L. Coudreuse, L.C. Dufour, E. Finot, Corros. Sci. 45 (2003) 1143.

[12] M. Hayakawa, S. Matsuoka, K. Tsuzaki, Mater. Trans. 43 (2002) 1758.

[13] J. Polák, J. Man, K. Orbtlík, Int. J. Fatigue 25 (2003) 1027.

[14] D. Chandrasejkaran, M. Nygårds, Acta Mater. 51 (2003) 5375.

[15] H. Hirukawa, S. Matsuoka, K. Miyahara, Y. Furuya, Mater. Lett. 58 (2004) 321.

[16] O. Santos, T. Nylander, R. Rosmaninho, G. Rizzo, S. Yiantsios, A. Karebelas, H. Müller-Steinhagen, L. Melo, L. Boulangé-Petermann, C. Gabet, A. Braem, C. Trägårdh, M. Paulsson, J. Food Eng. 64 (2004) 63.

[17] Y.H. Guu, Appl. Surf. Sci. 242 (2005) 245.

[18] W. Sun, A.K. Tieu, Z. Jiang, H. Zhiu, C. Lu, J. Mater. Proc. Technol. 155-156 (2004) 1300.

[19] E.E. Rees, M.P. Tryan, D.S. McPhail, Electrochem. Solid State Lett. 5 (2002) B21.

[20] C.M.A. Brett, P.I.C. Melo, J. Appl. Electrochem. 27 (1997) 959. 
[21] V.A. Alves, C.M.A. Brett, A. Cavaleiro, J. Appl. Electrochem. 31 (2001) 65.

[22] V.A. Alves, C.M.A. Brett, A. Cavaleiro, Rev. Corros. Prot. Mater. 20 (2001) 17.

[23] V.A. Alves, C.M.A. Brett, Corros. Sci. 44 (2002) 1949.

[24] V.A. Alves, C.M.A. Brett, Electrochim. Acta 47 (2002) 2081.

[25] A. Aldykiewicz, H.S. Isaacs, Report No. 60099, Brookhaven National Laboratory, Long Island, NY, 1994.

[26] E. Schmidt-Rieder, X.Q. Tong, J.P.G. Farr, M. Aindow, Br. Corros. J. 31 (1996) 139.

[27] Y.F. Cheng, J.L. Luo, J. Electrochem. Soc. 146 (1999) 970.

[28] V. Alves, C.M.A. Brett, M.F. Montemor, Quim. Nova 28 (2005) 204. 